\title{
NOTE
}

\section{Comparison between the Antimicrobial Activity of Essential Oils and Their Components in the Vapor Phase against Food-related Bacteria}

\author{
Ayaka Nakamura, Asuka Kawahara, Hajime Takahashi*, Takashi Kuda, and Bon Kimura \\ Department of Food Science and Technology, Tokyo University of Marine Science and Technology, 4-5-7 Konan, Minato-ku, Tokyo 108-8477, \\ JAPAN
}

\begin{abstract}
In this study, the antibacterial properties of the volatile components of four essential oils (cinnamon, clove, origanum, and peppermint oil) and five of their components (allyl isothiocyanate (AITC), carvacrol, citral, eugenol, and (+)-limonene) against five food-related bacteria (Escherichia coli, Listeria monocytogenes, Salmonella Typhimurium, Pseudomonas fluorescens, and Enterococcus faecalis) were evaluated. The results of disc volatilization method revealed that AITC exhibited antibacterial activity against the five tested strains at the lowest concentration, as did cinnamon oil and carvacrol. Moreover, the total aerobic bacterial count in coleslaw salad was suppressed in all test groups treated with AITC compared to that in control.
\end{abstract}

Key words: essential oils, active packaging, shelf life, volatile component, antimicrobial activity

\section{Introduction}

Currently, there are many different types of materials used for food packaging, and technologies, such as oxygen and water vapor barrier technology, which have been developed to prevent the loss of flavors and physical properties of food ${ }^{1}$. Conversely, the growth of microorganisms, which is an internal factor, also has a great impact on the food quality. Therefore, in addition to the barrier technology, techniques that actively suppress the growth of microorganisms in food are urgently required. "Active packaging" is a term that describes the method of packaging wherein a technology to improve the food quality has actively been applied ${ }^{2,3)}$. A recent study has described the method of active packaging using a technology to inhibit the growth of microorganisms inside food packages ${ }^{4,5}$. This method of packaging is expected to extend the expiration date of the food products.

Active packaging can be categorized into two main groups: i) non-migratory active packaging that adheres directly to food surface; and ii) active release packaging that releases antimicrobial substances into the headspace of food packages without directly coming in contact with $\operatorname{food}^{4)}$. Particularly, active release packaging has been com- mercially applied through adding sachets or pads containing antibacterial agents within the packages ${ }^{6,7)}$. Many of the active release packaging methods that has been commercialized and applied for food packaging utilizes ethanol vapors, such as Ethicap ${ }^{\mathrm{TM}}$, Antimold $102^{\mathrm{TM}}$, Negamold ${ }^{\mathrm{TM}}$ (Freund Industrial Co. Ltd., Japan), Age-less ${ }^{\mathrm{TM}}$ type SE (Mitsubishi Gas Chemical Co. Ltd., Japan), and Fretek1 $(\text { Techno Intl. Inc., USA })^{8}$. Products using these ethanol vapors are often applied to suppress the growth of molds. Furthermore, to broaden the antibacterial spectrum of active release packaging, growing attention has been paid to the antibacterial properties of the volatile components of essential oils $(\mathrm{EOs})^{9)}$.

EOs are volatile aromatic oils extracted from the flowers, leaves, and stems of plants, and some EOs and their major components exhibit antibacterial and antioxidant properties $^{10,11)}$. Due to their high volatility, EOs can evaporate in the food packages and can likely be used as an alternative antibacterial substance to ethanol. Many studies on the antibacterial properties of volatile components of EOs have been reported thus far $^{12-15)}$, and some studies have compared the antibacterial properties of different types of EOs against multiple bacteria, including gram-positive and

\footnotetext{
*Correspondence to: Hajime Takahashi, Department of Food Science and Technology, Tokyo University of Marine Science and Technology, 4-5-7 Konan, Minato-ku, Tokyo 108-8477, JAPAN

E-mail: hajime@ kaiyodai.ac.jp

Accepted November 16, 2021 (received for review October 30, 2021)

Journal of Oleo Science ISSN 1345-8957 print / ISSN 1347-3352 online

http://www.jstage.jst.go.jp/browse/jos/ http://mc.manusriptcentral.com/jjocs

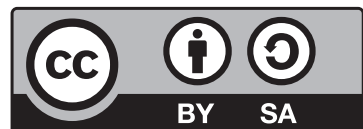


gram-negative bacteria, under the same conditions ${ }^{16-18)}$. Furthermore, most prior studies examined the antibacterial activity of the volatile components of EOs using experimental systems that affixed patches or filter papers soaked in EOs to the insides of petri dishes ${ }^{19-23)}$. However, volatile vapors may pass through polystyrene petri dishes and parafilm. To accurately evaluate the antibacterial properties of EOs and their components, it is necessary to design experiments in which they do not pass through to the outside. Numerous publications have shown data on the composition of various EOs. The detailed composition of the EO or its headspace has often been analyzed via gas chromatography and mass spectrometry ${ }^{24-26)}$. The EO consists of over 60 individual components ${ }^{27)}$, but its main components comprise up to $85 \%$ of its composition ${ }^{10)}$. For example, origanum oil is composed of components such as carvacrol (from trace amounts to $80 \%$ ) and thymol(from trace amounts to $64 \%$ ), while the main component of clove is eugenol $(75-85 \%)^{10)}$. However, it has been reported that not only the main components but also other minor components, present in trace amounts, contribute to the antibacterial properties of $\mathrm{EO}^{28,29)}$. Therefore, when evaluating the antibacterial properties of EO, it is necessary to evaluate the antibacterial properties of both EO as a whole and its individual components. In this study, we selected the essential oils (origanum oil, peppermint oil, clove oil, and cinnamon oil) in which the constituents of EO had already been determined. Furthermore, allyl isothiocyanate, limonene, citral, carvacrol, and eugenol, which are well reported as constituents of $\mathrm{EO}$, in addition to the having the pure product being sold as a reagent, were selected. EO and EO components were selected because they are approved for use as food additives and can be added to foods to enhance their sensual dimension.

In this study, we aimed to provide information on the most effective EOs and their components in vapor phase against food-related bacteria. To achieve this goal, the antibacterial properties of different EOs (cinnamon, clove, origanum, and peppermint oil) and EO components (AITC, carvacrol, citral, eugenol, and (+)-limonene) against five food-related bacteria (Escherichia coli, Salmonella Typhimurium, Listeria monocytogenes, Pseudomonas fluorescens, and Enterococcus faecalis) in the vapor phase were compared under the same conditions. Further, the preservative effectiveness of applying AITC, which exhibited strong antibacterial activity, to active packaging for coleslaw were evaluated.

\section{Materials and Methods}

\subsection{Preparation of test strain}

All tests were performed against two gram-positive[ Listeria monocytogenes (CIP103575) which obtained from
Collection of the Institute Pasteur (CIP) and Enterococcus faecalis (JCM5803) which obtained from Japan Collection of Microorganism (JCM)] and three gram-negative[Escherichia coli (ATCC11775) and Salmonella Typhimurium (ATCC13311) which obtained from American Type Culture Collection (ATCC), and Pseudomonas fluorescens (IFO14160) which obtained from Institute for Fermentation, Osaka (IFO) ] food-related bacteria.

The strains stored at $-80^{\circ} \mathrm{C}$ were inoculated into $10 \mathrm{~mL}$ of suitable broth media. De Man, Rogosa, and Sharpe (MRS) broth (Merck, Darmstadt, Germany)was used for culturing E. faecalis and trypticase soy broth(TSB) (Becton, Dickinson and Company, US) was used for the other strains. The strains were cultured overnight at suitable temperature $\left(37^{\circ} \mathrm{C}\right.$ for $E$. coli and $S$. Typhimurium, $30^{\circ} \mathrm{C}$ for $E$. faecalis and L. monocytogenes, and $25^{\circ} \mathrm{C}$ for $P$. fluorescens) to obtain the precultures. Then, $10 \mu \mathrm{L}$ of each preculture was inoculated into $10 \mathrm{~mL}$ of suitable broth (MRS for E. faecalis, TSB for the other strains) and cultured overnight at a suitable temperature (described above) to obtain bacterial suspension at a concentration of $9 \log \mathrm{CFU} / \mathrm{mL}$.

\subsection{Essential oils (EOs) and their components}

Four types of EOs: Origanum oil (Tokyo Chemical Industry), peppermint oil(KISHIDA chemical), cinnamon oil (KISHIDA chemical Co., Ltd., Osaka, Japan) and clove oil (KISHIDA chemical), and Five types of EO components: AITC (Fuji Film Wako Pure Chemical Industries, Ltd., Osaka, Japan), carvacrol (Tokyo Chemical Industry Co., Ltd., Tokyo, Japan), citral (Tokyo Chemical Industry), eugenol (Tokyo Chemical Industry) and (+ )-limonene (Tokyo Chemical Industry), were used.

\subsection{Evaluation of antibacterial activity of EOs and their components in vapor phase}

In vitro antibacterial activity of EOs and their components in vapor phase was evaluated using the disc volatilization method at 22 different concentrations (0.04-15.72 $\left.\mu \mathrm{L} / \mathrm{cm}^{3}\right)$. First, about $20 \mathrm{~mL}$ of medium was poured into the plastic petri dish[diameter $(\mathrm{d})=52 \mathrm{~mm}$, height $(\mathrm{h})=$ $2.4 \mathrm{~mm}$ ]. MRS agar medium was used for culturing $E$. faecalis, and trypticase soy agar(TSA) (Becton, Dickinson and Company) for other bacteria. After the solidification of the medium, $10^{5} \mathrm{CFU} / \mathrm{mL}$ of each bacterium were spread onto the surface of the medium. Then, different doses of EOs $(2.5,5,10,25,50,100,150,200,250,300,350,400$, $450,500,550,600,650,700,750,800,900$, and $1000 \mu \mathrm{L})$ were added to each 9 -mm sterile blank paper discs (Toyo Roshi Kaisha, Ltd., Tokyo, Japan), which were placed on the cover of each petri dish. Finally, the entire petri dish was wrapped in TECHBARRIER ${ }^{\mathrm{TM}}$ film (Mitsubishi Chemical Co., Tokyo, Japan), which had gas barrier property, to avoid diffusion of the volatile components outside the dish. 
The petri dishes were incubated for $24 \mathrm{~h}$ at the optimum temperature for the growth of each bacterium as described above. After incubation, the bacterial growth on the medium was confirmed, and the minimum concentration of each EO and their components that completely inhibited the growth was defined as the minimal inhibitory concentration (MIC).

\subsection{Antibacterial activity of AITC in food packaging}

AITC, which was confirmed to exhibit the highest antibacterial activity, was investigated for its effect on suppressing the bacterial growth through measuring the general bacterial counts in food, when applied to the food packaging. At first, coleslaw was prepared using the following procedure. Initially, cabbage, mayonnaise, and table salt were purchased from a retail store. Then, the outermost three leaves and the central core of the cabbage were removed and discarded. The remaining leaves were washed and cut into $5-\mathrm{mm}^{2}$ pieces using a food processor. The cabbage leaf squares were mixed with $10 \%$ (w/w) mayonnaise. About $25 \mathrm{~g}$ of coleslaw salad was placed in a PET container ( $d=129 \mathrm{~mm}, \mathrm{~h}=48 \mathrm{~mm}$; capacity: $360 \mathrm{~mL}$ ) (AS ONE Corporation, Osaka, Japan) and covered with a TECHBARRIER $^{\mathrm{TM}}$ film. Filter paper (diameter, $90 \mathrm{~mm}$ ) impregnated with $2.5,15$, and $25 \mu \mathrm{L} \operatorname{AITC}(0.007,0.04$, and $0.07 \mu \mathrm{L} / \mathrm{cm}^{3}$, respectively) were placed on top of the PET container inside the food packages to avoid direct contact with the coleslaw. Additionally, a control of just coleslaw was prepared and placed on filter paper without AITC on the top of the PET container to match the conditions of the other test plots. Coleslaw was stored at $10^{\circ} \mathrm{C}$ for 7 days, and the number of total aerobic bacteria was counted on days $0,3,5$, and 7 .

\subsection{Statistical analysis}

All tests were conducted in triplicate $(n=3)$. The results are presented as the mean \pm standard error. The statistical analysis was performed using EXCEL statistical Ver. 6.0 software (Esumi, Tokyo, Japan). In the coleslaw experiment, individual mean values of the experimental groups were compared with control at each sampling day, and the significance of differences was evaluated using the Dunnett's post hoc test with the level of statistical significance set at $p<0.01$.

\section{Results and Discussion}

\subsection{Antibacterial activity evaluation of EOs and their com- ponents}

In this study, the antibacterial activities of EOs and their volatile components against five food-related bacteria were evaluated. To prevent the transmission of EO volatile components to the outside of the dishes, we covered the petri dishes with a gas barrier film and designed an experiment to accurately evaluate the antibacterial activity of EOs and their components.

It was found that AITC exhibited the highest antibacterial activity amongst the EOs and EO components tested in this study. Its MIC against gram-negative bacteria (E. coli, $S$. Typhimurium, and P. fluorescens) was less than $0.02 \mu \mathrm{L} /$ $\mathrm{cm}^{3}$, which was the lowest value obtained in this experiment, and its MIC values for gram-positive bacteria $(L$. monocytogenes and E. faecalis) were $0.05 \pm 0.02$ and 0.07 $\pm 0.06 \mu \mathrm{L} / \mathrm{cm}^{3}$, respectively (Figs. $1 \mathrm{~A}-1 \mathrm{E}$ ). Most previous studies evaluated the antibacterial activity of a single EO, and few have compared the antibacterial activity of more than nine different $\mathrm{EOs}^{30-35)}$. In this study, the antibacterial properties of four EOs and five EO components were evaluated simultaneously, and AITC was identified as the most effective against five types of bacteria tested in this experiment. AITC is extracted from plants belonging to the Cruciferae family, such as wasabi and mustard ${ }^{36)}$. AITC is an organic sulfur compound containing an isothiocyanate group and is known to have a small molecular weight of 99.15 $\left(\mathrm{C}_{4} \mathrm{H}_{5} \mathrm{NS}\right)$ and high volatility. In this experiment, the petri dishes were incubated at $25-37^{\circ} \mathrm{C}$, to match the optimum growth temperature of the test strains. Therefore, it was considered that AITC easily volatilized and showed strong antibacterial properties under these temperature conditions.

The MIC values of carvacrol and cinnamon oil against these five strains were $1.31-3.14 \mu \mathrm{L} / \mathrm{cm}^{3}$ and $1.31-2.62 \mu \mathrm{L} /$ $\mathrm{cm}^{3}$, respectively (Figs. 1A-1E), which represent relatively high antibacterial activity against the five strains, followed by AITC. Upon comparing the four EOs and five EO components, similar concentrations of carvacrol and cinnamon oil were found to suppress the growth of the five strains regardless of their type, indicating their wide antibacterial spectrums.

The MIC values of the other six EOs differed greatly depending on the strain. The MIC values of eugenol and origanum oil for four strains other than $P$. fluorescens were between $3.14-4.98 \mu \mathrm{L} / \mathrm{cm}^{3}$ and $1.32-2.62 \mu \mathrm{L} / \mathrm{cm}^{3}$, respectively (Figs. 1A, 1B, 1D, 1E). For P. fluorescens, their MIC values were as high as 12.32 and $13.36 \mu \mathrm{L} / \mathrm{cm}^{3}$, respectively (Fig. 1C). Similar results were obtained for clove oil. Its MIC values for the four strains excluding $P$. fluorescens were relatively low ranging between $3.14-5.50 \mu \mathrm{L} / \mathrm{cm}^{3}$ (Figs. 1A, 1B, 1D, 1E), but the MIC value for $P$. fluorescens was the highest at $15.72 \mu \mathrm{L} / \mathrm{cm}^{3}$ (Fig. 1C), showing that it did not suppress the bacterial growth. These results indicate that eugenol, origanum oil, and clove oil did not exhibit high antibacterial activities against $P$. fluorescens. Previous studies have also shown that Pseudomonas has low sensitivity to EOs, which may be related to the barrier functions of their outer membranes or energy functions ${ }^{37)}$. This indicates that the differences in cell membrane func- 
A

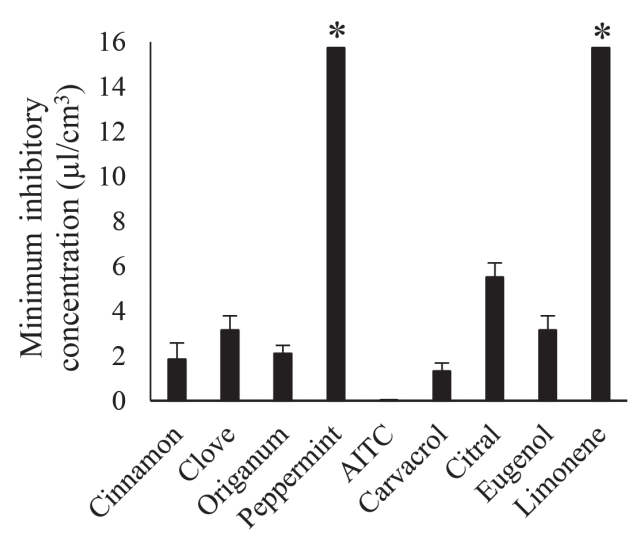

C

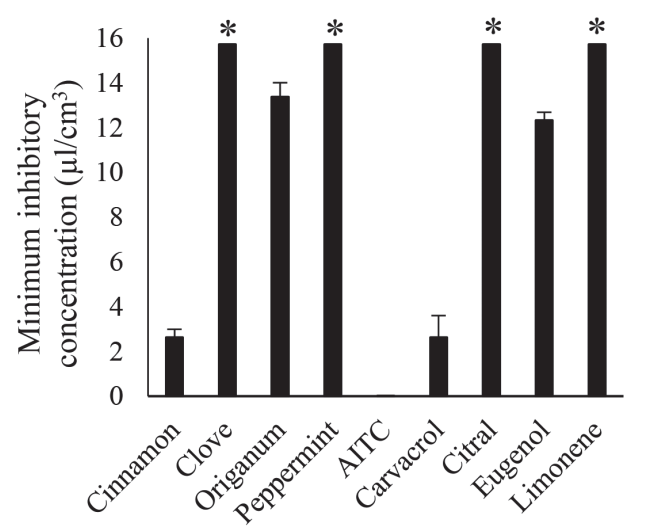

$\mathrm{E}$

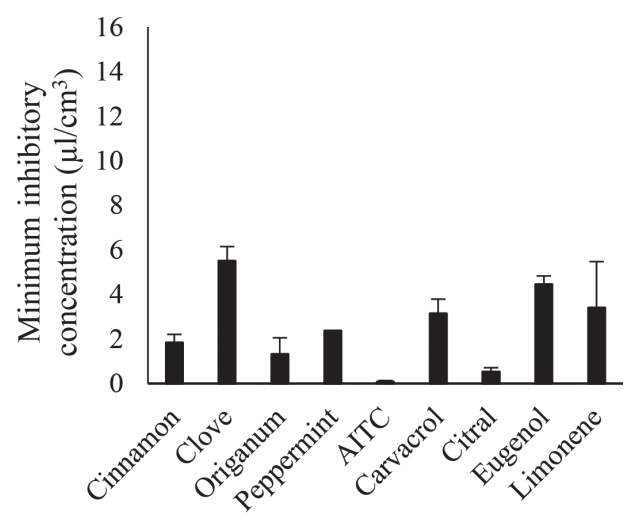

B

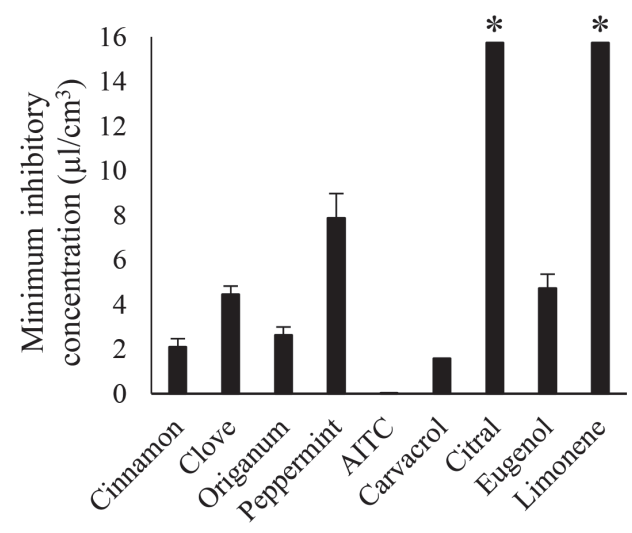

$\mathrm{D}$

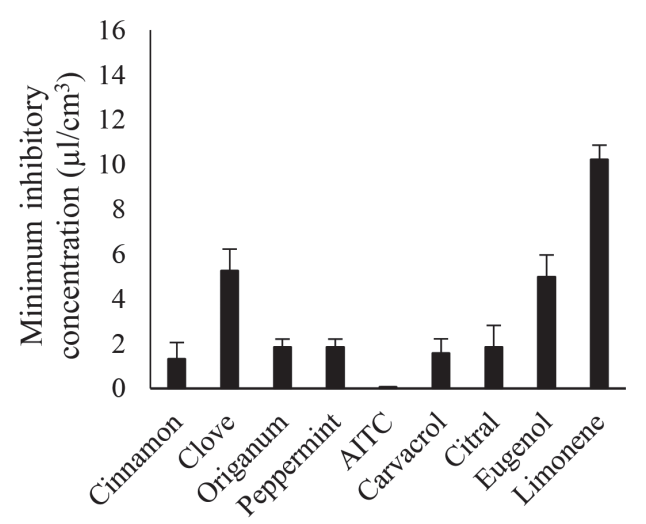

Fig. 1 MIC values $\left(\mu \mathrm{L} / \mathrm{cm}^{3}\right)$ of four essential oils and five essential oil components in the vapor phase against Escherichia coli(A), Salmonella Typhimurium(B), Pseudomonas fluorescens (C), Listeria monocytogenes (D), and Enterococcus faecalis $(\mathrm{E})$. Values are presented as the mean \pm standard error $(\mathrm{SE})(\mathrm{n}=3)$.

*Indicates that the growth inhibitory effect was not confirmed even at the highest concentration.

tions between different strains may contribute to their sensitivity to EOs.

Peppermint and citral also exhibited different antibacterial activities against the tested bacterial strains. Their MIC values for $L$. monocytogenes and $E$. faecalis were as low as $0.52-2.36 \mu \mathrm{L} / \mathrm{cm}^{3}$ (Figs. 1D, 1E), demonstrating high antibacterial activity against these gram-positive bacterial strains. Peppermint did not suppress the growth of $E$. coli 
Table 1 Total aerobic counts in coleslaw without AITC (Control), and with 0.007, 0.04 and $0.07 \mu \mathrm{L} / \mathrm{cm}^{3}$ of AITC, stored at $10^{\circ} \mathrm{C}$, for 7 days.

\begin{tabular}{rcccc}
\hline \multirow{2}{*}{$\begin{array}{c}\text { Concentration of AITC } \\
\left(\mu \mathrm{L} / \mathrm{cm}^{3}\right)\end{array}$} & \multicolumn{4}{c}{ Storage period (days) } \\
\cline { 2 - 5 } & 0 & 3 & 5 & 7 \\
\hline control & $3.95 \pm 0.02$ & $6.04 \pm 0.11$ & $8.19 \pm 0.02$ & $9.03 \pm 0.02$ \\
0.007 & $3.95 \pm 0.02$ & $4.89 \pm 0.06^{*}$ & $7.36 \pm 0.04$ & $8.74 \pm 0.05$ \\
0.04 & $3.95 \pm 0.02$ & $4.61 \pm 0.11^{*}$ & $6.22 \pm 0.18^{*}$ & $8.07 \pm 0.13^{*}$ \\
0.07 & $3.95 \pm 0.02$ & $4.50 \pm 0.07^{*}$ & $5.57 \pm 0.27^{*}$ & $7.57 \pm 0.16^{*}$ \\
\hline
\end{tabular}

The values represent the mean $\pm \mathrm{SE}(\mathrm{n}=3)$.

Significant difference between control (without AITC) and sample (with AITC) on the same day was shown as $*(p<0.01)$.

or P. fluorescens, and citral did not suppress the growth of $S$. Typhimurium or $P$. fluorescens, exhibiting no antibacterial activity even at a concentration as high as $15.72 \mu \mathrm{L} / \mathrm{cm}^{3}$ (Figs. 1A, 1B, 1C). The MIC value of limonene for $E$. faecalis was as low as $3.41 \mu \mathrm{L} / \mathrm{cm}^{3}$, thereby exhibiting high antibacterial activity (Fig. 1E). However, the MIC value for L. monocytogenes was as high as $10.22 \mu \mathrm{L} / \mathrm{cm}^{3}$ (Fig. 1D), and it exhibited no antibacterial activity against the three gram-negative bacteria (Figs. 1A, 1B, 1C). These results indicated that EOs and $\mathrm{EO}$ components exhibited different antibacterial activities depending on the bacterial strains. Several previous studies have shown that the antibacterial effects of the volatile components of EOs differ depending on the bacterial species ${ }^{10)}$, which is also consistent with our results. Therefore, the application of EOs and their components may be possible widely through selecting specific EOs for certain bacterial strains or through combining them.

\subsection{Antibacterial activity of AITC in food packaging}

As AITC exhibited the lowest MIC values for the five strains, its antibacterial activity when applied to food packages designed to simulate active packaging was evaluated. AITC is a pungent ingredient such as wasabi and mustard, and the foods that can be used are limited, with respect to their sensual dimension. Some coleslaw recipes use mustard, where the main ingredient, mayonnaise, helps mask the odorous components of AITC. Therefore, in this study, using coleslaw salad as a model food, we evaluated whether the expiration date could be extended using the total aerobic bacterial count as an indicator.

When 2.5, 15, or $25 \mu \mathrm{L}$ of AITC were applied to the food packaging, the concentrations of AITC per headspace were 0.007, 0.04, and $0.07 \mu \mathrm{L} / \mathrm{cm}^{3}$, respectively. Even if we assume that all the added AITC volatilized and got exposed to the coleslaw, since the amount of AITC was at most $0.0001 \%(\mathrm{v} / \mathrm{w})$ of the weight of coleslaw, its effect on the flavor would be negligible.

The total aerobic count was suppressed in all test groups when AITC was added compared to that of control (Table
1). Even with the smallest amount of AITC $[2.5 \mu \mathrm{L}(0.007$ $\left.\left.\mu \mathrm{L} / \mathrm{cm}^{3}\right)\right]$, the bacterial count on day 3 was $4.9 \log \mathrm{CFU} / \mathrm{g}$, which was $1.1 \log$ CFU/g lower than that of control. The addition of $15 \mu \mathrm{L}\left(0.04 \mu \mathrm{L} / \mathrm{cm}^{3}\right)$ of AITC significantly suppressed the bacterial counts $(p<0.01)$, which on days 3 and 5 were 4.6 and $6.2 \log \mathrm{CFU} / \mathrm{g}$, respectively, which were 1.4 and $2.0 \log \mathrm{CFU} / \mathrm{g}$ lower than that of control. The addition of $25 \mu \mathrm{L}\left(0.07 \mu \mathrm{L} / \mathrm{cm}^{3}\right)$ of AITC significantly suppressed the bacterial counts $(p<0.01)$. The counts on days 3 and 5 were 4.5 and $5.6 \log \mathrm{CFU} / \mathrm{g}$, respectively, which were 1.5 and $2.6 \log \mathrm{CFU} / \mathrm{g}$ lower than that of control. This result indicates that the application of the volatile components of AITC to active packaging effectively reduced the bacterial count in coleslaw.

Generally, in experiments that evaluate the antibacterial activity of EOs in food, to obtain the same effects as in vitro experiments, it is necessary to use higher concentrations of $\mathrm{EOs}^{38,39)}$. This is thought to be because foods have a more complex environment than culture mediums, and various factors including $\mathrm{pH}$, water activity, carbohydrates, fats, and proteins act to inhibit the antibacterial effect ${ }^{40-42}$. In previous studies, when AITC was added directly to food, to reduce the viable bacterial count, it was necessary to add AITC at approximately $1.0 \%$ of the food weight ${ }^{33)}$. However, in the present study, because the antimicrobial and other volatile components of AITC were transpired into the headspace of the packaging, the surface of the food was exposed to AITC without it coming into direct contact with the food, which resulted in no loss of antibacterial activity. This indicates that applying the volatile components of AITC to active packaging effectively reduced the bacterial count in coleslaw.

\section{Conclusion}

In this study, we demonstrated the antibacterial activity of four EOs and five EO components against five food-related bacteria. Particularly, the volatile components of AITC exhibited the strongest antibacterial activity and 
even a small amount of AITC was able to suppress the bacterial growth. AITC also exhibited strong antibacterial activity when applied to the food packages. This indicates that AITC could be used as an antimicrobial component in active packaging.

\section{Conflict of Interest}

The authors declare there are no conflicts of interest.

\section{Author Contributions}

Ayaka Nakamura: Conception and design of study, Acquisition of data, Drafting the manuscript. Asuka Kawahara: Acquisition of data, Analysis and/or interpretation of data. Hajime Takahashi: Conception and design of study, Revising the manuscript critically for important intellectual content. Takashi Kuda: Revising the manuscript critically for important intellectual content. Bon kimura: Revising the manuscript critically for important intellectual content.

\section{References}

1) Marsh, K.; Bugusu, B. Food packaging - Roles, materials, and environmental issues: Scientific status summary. J. Food Sci. 72, 39-55(2007).

2) Prasad, P.; Kochhar, A. Active packaging in food industry: A Review. IOSR J. Environ. Sci. Toxicol. Food Technol. 8, 1-7(2014).

3) Soltani Firouz, M.; Mohi-Alden, K.; Omid, M.A. Critical review on intelligent and active packaging in the food industry: Research and development. Food Res. Int. 141, 110-113(2021).

4) Mousavi Khaneghah, A.; Hashemi, S.M.B.; Limbo, S. Antimicrobial agents and packaging systems in antimicrobial active food packaging: An overview of approaches and interactions. Food Bioprod. Process. 111, 1-19(2018).

5) Suppakul, P.; Miltz, J.; Sonneveld, K.; Bigger, S.W. Active packaging technologies with an emphasis on antimicrobial concise reviews in food science. J. Food Sci. 68, 408-420 (2003).

6) Lü, F.; Ye, X.; Liu, D. Review of antimicrobial food packaging. Nongye Jixie Xuebao/Transactions Chinese Soc. Agric. 40, 138-142(2009).

7) Otoni, C.G.; Espitia, P.J.P.; Avena-bustillos, R.J.; Mchugh, T.H. Trends in antimicrobial food packaging systems: Emitting sachets and absorbent pads. Food Res. Int. 83, 60-73 (2016).

8) Kapetanakou, A.E; Skandamis, P.N. Applications of active packaging for increasing microbial stability in foods: Natural volatile antimicrobial compounds. Curr. Opin. Food Sci. 12, 1-12 (2016).

9) Ju, J.; Chen, X.; Xie, Y.; Yu, H.; Guo, Y. et al. Application of essential oil as a sustained release preparation in food packaging. Trends Food Sci. Technol. 92, 22-32 (2019).

10) Burt, S. Essential oils: Their antibacterial properties and potential applications in foods - A review. Int. J. Food Microbiol. 94, 223-253(2004).

11) Calo, J.R.; Crandall, P.G.; O’Bryan, C.A.; Ricke, S.C. Essential oils as antimicrobials in food systems - A review. Food Control. 54, 111-119 (2015).

12) Aguilar-González, A.E.; Palou, E.; López-Malo, A. Antifungal activity of essential oils of clove (Syzygium aromaticum) and/or mustard (Brassica nigra) in vapor phase against gray mold (Botrytis cinerea) in strawberries. Innov. Food Sci. Emerg. Technol. 32, 181-185 (2015).

13) Goñi, P.; López, P.; Sánchez, C.; Gómez-Lus, R.; Becerril, R.; Nerín, C. Antimicrobial activity in the vapour phase of a combination of cinnamon and clove essential oils. Food Chem. 116, 982-989 (2009).

14) Hyun, J.E.; Bae, Y.M.; Yoon, J.H.; Lee, S.Y. Preservative effectiveness of essential oils in vapor phase combined with modified atmosphere packaging against spoilage bacteria on fresh cabbage. Food Control, 51, 307-313 (2015).

15) Reyes-Jurado, F.; Cervantes-Rincón, T.; Bach, H.; López-Malo, A.; Palou, E. Antimicrobial activity of Mexican oregano (Lippia berlandieri), thyme(Thymus vulgaris), and mustard (Brassica nigra) essential oils in gaseous phase. Ind. Crops Prod. 131, 90-95 (2019).

16) Goñi, P.; López, P.; Sánchez, C.; Gómez-Lus, R.; Becerril, R.; Nerín, C. Antimicrobial activity in the vapour phase of a combination of cinnamon and clove essential oils. Food Chem. 116, 982-989 (2009).

17) Kloucek, P.; Smid, J.; Frankova, A.; Kokoska, L.; Valterova, I.; Pavela, R. Fast screening method for assessment of antimicrobial activity of essential oils in vapor phase. Food Res Int. 47, 161-165(2012).

18) López, P.; Sánchez, C.; Batlle, R.; Nerín, C. Solid- and vapor-phase antimicrobial activities of six essential oils: Susceptibility of selected foodborne bacterial and fungal strains. J. Agric Food Chem. 53, 6939-6946 (2005).

19) Du, W.X.; Olsen, C.W.; Avena-Bustillos, R.J.; McHugh, T.H.; Levin, C.E.; Mandrell, R.; Friedman, M. Antibacterial effects of allspice, garlic, and oregano essential oils in tomato films determined by overlay and vaporphase methods. J. Food Sci. 74, 390-397 (2009).

20) López, P.; Sánchez, C.; Batlle, R.; Nerín, C. Solid- and vapor-phase antimicrobial activities of six essential oils: Susceptibility of selected foodborne bacterial and 
fungal strains. J. Agric. Food Chem. 53, 6939-6946 (2005).

21) Ozin, B.I.B.; Ukic, N.E.D.A.M.I.; Imin, N.A.S.; Nackov, G.O.A. Characterization of the volatile composition of essential oils of some lamiaceae spices and the antimicrobial and antioxidant activities of the entire oils. $J$. Agric. Food Chem. 54, 1822-1828 (2006).

22) Rodr, A.; Batlle, R.; Ner, C. The use of natural essential oils as antimicrobial solutions in paper packaging. Part II. Prog. Org. Coat. 60, 33-38 (2007).

23) Wang, T.; Hsia, S.; Wu, C.; Ko, S.; Chen, Y. et al. Evaluation of the antibacterial potential of liquid and vapor phase phenolic essential oil compounds against oral microorganisms. PLoS One 11, 1-17(2016).

24) Daferera, D.J.; Ziogas, B.N.; Polissiou, M.G. GC-MS analysis of essential oils from some Greek aromatic plants and their fungitoxicity on Penicillium digitatum. J. Agric. Food Chem. 48, 2576-2581 (2000).

25) Delaquis, P.J.; Stanich, K.; Girard, B.; Mazza, G. Antimicrobial activity of individual and mixed fractions of dill, cilantro, coriander and eucalyptus essential oils. Int. J. Food Microbiol. 74, 101-109 (2002).

26) Jerković, I.; Mastelić, J.; Miloš, M. The impact of both the season of collection and drying on the volatile constituents of Origanum vulgare L. ssp. hirtum grown wild in Croatia. Int. J. Food Sci. Technol. 36, 649-654 (2001).

27) Russo, M.; Galletti, G.C.; Bocchini, P.; Carnacini, A. Essential oil chemical composition of wild populations of Italian oregano spice (Origanum vulgare ssp. hirtum (Link) Ietswaart): A preliminary evaluation of their use in chemotaxonomy by cluster analysis. 1. Inflorescences. J. Agric. Food Chem. 46, 3741-3746 (1998).

28) Marino, M.; Bersani, C.; Comi, G. Impedance measurements to study the antimicrobial activity of essential oils from Lamiaceae and Compositae. Int. J. Food Microbiol. 67, 187-195(2001).

29) Paster, N.; Menasherov, M.; Ravid, U.; Juven, B. Antifungal activity of oregano and thyme essential oils applied as fumigants against fungi attacking stored grain. J. Food Prot. 58, 70-75 (1995).

30) Adukwu, E.C.; Bowles, M.; Edwards-jones, V.; Bone, H. Antimicrobial activity, cytotoxicity and chemical analysis of lemongrass essential oil (Cymbopogon flexuosus) and pure citral. Appl. Microbiol. Biotechnol. 100, 9619-9627 (2016).

31) Arfa, A. Ben; Combes, S.; Gontard, N.; Chalier, P. Antimicrobial activity of carvacrol related to its chemical structure. Lett. Appl. Microbiol. 43, 149-154(2006).

32) Dufour, V.; Alazzam, B.; Ermel, G.; Thepaut, M.; Rossero, A. et al. Antimicrobial activities of isothiocyanates against Campylobacter jejuni isolates. Front. Cell Infect. Microbiol. 2, 1-13(2012).
33) Olaimat, A.N.; Al-Holy, M.A.; Abu Ghoush, M.; AlNabulsi, A.A.; Holley, R.A. Control of Salmonella enterica and Listeria monocytogenes in hummus using allyl isothiocyanate. Int. J. Food Microbiol. 278, 73-80 (2018).

34) Shi, C.; Song, K.; Zhang, X.; Sun, Y.; Sui, Y. et al. Antimicrobial activity and possible mechanism of action of citral against Cronobacter sakazakii. PLoS One 11, 1-12 (2016).

35) Wieczy, J.; Cavoski, I. Antimicrobial, antioxidant and sensory features of eugenol, carvacrol and trans-anethole in active packaging for organic ready-to-eat iceberg lettuce. Food Chem. 259, 251-260 (2018).

36) Tunc, S.; Chollet, E.; Chalier, P.; Preziosi-Belloy, L.; Gontard, N, Combined effect of volatile antimicrobial agents on the growth of Penicillium notatum. Int. J. Food Microbiol. 113, 263-270 (2007).

37) Mann, C.M.; Cox, S.D.; Markham, J.L. The outer membrane of Pseudomonas aeruginosa NCTC 6749 contributes to its tolerance to the essential oil of Melaleuca alternifolia (tea tree oil). Lett. Appl. Microbiol. 30, 294-297 (2000).

38) Gutierrez, J.; Barry-Ryan, C.; Bourke, P. The antimicrobial efficacy of plant essential oil combinations and interactions with food ingredients. Int. J. Food Microbiol. 124, 91-97 (2008).

39) Perricone, M.; Arace, E.; Corbo, M.R.; Sinigaglia, M.; Bevilacqua, A. Bioactivity of essential oils: a review on their interaction with food components. Front. Microbiol. 6, 1-7 (2015).

40) Canillac, N.; Mourey, A. Effects of several environmental factors on the anti-Listeria monocytogenes activity of an essential oil of Picea excelsa. Int. J. Food Microbiol. 92, 95-103 (2004).

41) Higueras, L.; López-Carballo, G.; Hernández-Muñoz, P.; Catalá, R.; Gavara, R. Antimicrobial packaging of chicken fillets based on the release of carvacrol from chitosan/cyclodextrin films. Int. J. Food Microbiol. 188, 53-59 (2014).

42) Requena, R.; Vargas, M.; Chiralt, A. Eugenol and carvacrol migration from $\mathrm{PHBV}$ films and antibacterial action in different food matrices. Food Chem. 277, 38-45 (2019).

CC BY-SA 4.0 (Attribution-ShareAlike 4.0 International). This license allows users to share and adapt an article, even commercially, as long as appropriate credit is given and the distribution of derivative works is under the same license as the original. That is, this license lets others copy, distribute, modify and reproduce the Article, provided the original source and Authors are credited under the same license as the original. 